\title{
EL PELIGRO YANKEE
}

Carlos Arturo Torres

Tuestro colega La Correspondencia, consecuente con su poético 1 amor al pasado y a esta mágica palabra: tradición, no encubre sus simpatías por la causa de España. Acaso sin quererlo, cohonesta tal orgánica y en ella noble tendencia con el temor de que con la intervención americana los cubanos no hagan sino cambiar de amo.

El asunto merece estudiarse. No creemos en la anexión, ni podemos pensar en ella sin profunda repugnancia: el prejuicio secular es por esta vez superior en nosotros a los modernos conceptos y a los modernos estudios etnográficos, que tan mal paradas dejan esas tradicionales clasificaciones de raza latina, raza sajona, que resultan más convencionales que científicas. Tal prejuicio nos hace ver con malos ojos la sajonización de la hermosa hermana. Concedamos, empero, en gracia de discusión, que la anexión fuera inevitable: ¿isignifica esto que los cubanos continuarán siendo esclavos, esto es, que pasarán a poder de otros amos?

Cedamos la palabra a un juez de la mayor excepción, a un español ilustradísimo y verdaderamente patriota, y que en esta ocasión ha demostrado tener más juicio que todos sus compatriotas, el señor $\mathrm{Pi}$ y Margall:

Inútil es también decirles (a los cubanos) que corren el peligro de que los Estados Unidos los absorban. No abrigan ese temor; $y$, cuando lo abrigaran, saben que unidos a la gran República serian un Estado verdaderamente autónomo. No tendrían entonces una Constitución otorgada, sino la Constitución que ellos dieran; no un Gobernador que el poder central Ies enviara, sino el Gobernador que ellos eligiesen; no los Tribunales constituidos y nombrados

DOI: http://dx.doi.org/10.18601/01245996.v17n33.14

${ }^{1}$ Publicado en La Opinión, 28 de abril de 1898. 
por el Gobierno de la República, sino los Tribunales que ellos constituyeran y nombraran. A un Tribunal Supremo tendrían dentro de su estado. Organizarían como quisieran su Administración, su Hacienda, su milicia; y en lo político, en lo económico, en lo civil, en lo penal, en lo religioso, se dictarían las leyes que creyeran más conformes a la índole de su pueblo y a su ideal de justicia. Se abrirían los mercados de toda la República para sus productos.

Ser Estado federal de la gran República ¿es, por ventura, ser esclavo? ¿Pudiera decirse que Alaska está hoy en peor condición política que cuando era colonia rusa, Louisiana y Florida peor que cuando eran colonias francesa y española, Tejas y California peor que cuando eran Estados mejicanos? Un plebiscito de los habitantes de esas comarcas sobre si querrían regresar a su antigua condición sería asaz instructivo en la materia. No. Ser ciudadanos de la gran República no es, no puede ser, estar en condición de esclavos. Lo es no tener derechos políticos como los cubanos bajo los españoles y los liberales bajo la Regeneración, aun cuando los que nos tiranizan sean de la misma raza y a las veces de raza inferior...

Los cubanos, entre ser ciudadanos americanos, como lo son muchísimos de ellos, Cisneros, Duque, Mora, etc., y ser súbditos españoles... no han vacilado; ¿por qué, si no, emigran en masa a la Florida $y$ se establecen allí con animus manendi $y$ se naturalizan yankees? De los veinte mil habitantes que tiene Cayo-Hueso, quince mil por lo menos son cubanos. Ellos se han anticipado a la anexión... luego será preferible a la sujeción colonial a España. Nadie podrá negar que el cubano es en esta ocasión el mejor juez de sus intereses.

Pero, con todo eso, nos repugna, decimos, la idea de la anexión; pero no la tememos. He aquí por qué:

Estudiar el desarrollo histórico de la doctrina Monroe y rastrear el espíritu de la cancillería de Washington en sus relaciones con los pueblos de Hispano-América es materia de varios y muy gruesos volúmenes. Urge, empero, analizar la razón histórica y política que pueda tener el ya general temor de que los americanos de los Estados Unidos no sólo atrapen a Cuba, sino que a la larga se absorban a todas estas repúblicas.

No negamos que tal es el deseo de algunos políticos yankees ni que algunos órganos de la prensa neoyorkina hayan hecho activa campaña en tal sentido. Tampoco está bien que neguemos que ocasiones ha habido en que el Gabinete se ha dejado contaminar por ese vértigo; mas también debemos consignar que las opiniones contrarias han prevalecido en la mayoría de los casos, y al lenguaje despectivo de muchos yankees podríamos oponer el lenguaje verdaderamente fraternal de muchos más. 
Opóngasenos la más ardiente cláusula anexionista a los siguientes conceptos del notable diplomático americano Henry Jackson:

Paralícese la mano que ose borrar una sola estrella de la pléyade de repúblicas americanas. ¡Muera el estadista que arranque pétalos o pistilos de una sola flor! Dejar a cada pueblo en el pleno goce de sus instituciones, costumbres y leyes locales; dejarlo gobernarse conforme a su agrado; si no consistiera en esto la libertad americana para todas las naciones, jentonces nuestras constituciones, la federal y las de los Estados, no serían más que mentiras, y nuestra bandera no sería más que una burla!

Mas rastreemos los hechos, que son más elocuentes que las palabras; examinemos si a la anexión de Tejas y California, el gran crimen hecho por los Estados esclavistas, que querían a todo trance aumentar territorios al Sur a fin de poner mayoría de congresales y evitar así leyes contra la esclavitud; examinemos si esa mancha, cuya explicación acabamos de dar, es parte a borrar del todo los actos que en sentido verdaderamente fraternal ha ejecutado la diplomacia de la gran República.

E1 distinguido escritor y ardiente patriota, señor Merchán, ha escrito sobre la materia un magistral estudio, que recomendamos a todos los que quieran conocer el asunto.

Los temores de que Cuba sea anexada a la gran República ¿son tan fundados que puedan ser parte, no sólo a amortiguar nuestro entusiasmo por la causa, sino a desear el triunfo de España y con él la continuación del despotismo en la Isla?

Creemos que no. Sin duda alguna hay americanos, y muchos, partidarios de la expansión territorial; pero no ha sido ésa en lo general la política de Washington en sus relaciones con los países latinos de América.

Las intervenciones del Gobierno de la gran República ¿han sido favorables o desfavorables a las repúblicas hispanas? Ésa es la cuestión que trataremos mañana.

\section{II $^{2}$}

La Europa, cuya causa es hoy tan simpática para algunos, aprovechó la gran guerra antiesclavista para hacer odiosas intentonas de monarquía y de coloniaje en América; entonces se efectuó la anexión de Santo Domingo a España, la intervención europea en Méjico, la guerra de España contra el Perú y Chile. Los Estados Unidos estaban empeñados en una guerra colosal; mas no bien se hubieron apagado los fuegos de ese vasto incendio, pidieron y obtuvieron de España la

\footnotetext{
${ }^{2}$ Publicado en La Opinión, 29 de abril de 1898.
} 
seguridad de que no atacaría a las Repúblicas del Pacífico en son de conquista, y el Gabinete de Washington declaró que "no permitiría la ocupación de las islas Chinchas ni de ninguno otro territorio de Chile o del Perú por los españoles".

Antes de esto, la enérgica actitud del secretario Seward había hecho retirar el ejército francés de Méjico e impedía también con su energía una intervención militar de Austria en Méjico. Nunca tampoco dejaron de reconocer el Gobierno republicano de Juárez.

Impidieron a Inglaterra la apropiación de grandes territorios en la América central, asegurando por medio del tratado Dallas Clarendon, la independencia de las Repúblicas centroamericanas.

Impidieron el cambio de la forma republicana, intentada por Europa en Méjico, Perú y Chile, y protestaron contra la anexión de Santo Domingo.

Cuando las potencias europeas, según se dijo, intentaban apoyar al Almirante Mello para restaurar el Imperio en el Brasil, los Estados Unidos manifestaron su voluntad de impedir el auxilio europeo a ese movimiento; gracias a esa actitud la restauración monárquica no se efectuó.

Se opusieron a las excesivas pretensiones de Inglaterra contra Nicaragua hace cinco años.

Intervinieron de un modo patriótico y decidido en la cuestión de límites entre Venezuela y la Guayana inglesa, de tal suerte, que Venezuela, invadida y despreciada hasta entonces, vio cesar súbitamente la detentación de sus derechos y recuperó el territorio invadido.

Estos son hechos, no palabras. ¿En dónde está la recompensa territorial que la gran República ha exigido por su actitud salvadora en todas esas grandes emergencias? Esto en lo relativo a intervención; en cuanto a anexión, cedemos la palabra a Merchán:

Mucho se habla de anexión; pero hay que confesar que fuera del Continente, y en extensión continua, los Estados Unidos no han llevado a efecto casi ninguna. Liberia pudiera ser de ellos; y la Sociedad que la fundó en 1816 la dejó libre tan pronto como a la Colonia le convino, en 24 de agosto de 1847, hace cerca de medio siglo.

E1 24 de octubre de 1867 ajustó la Administración Johnson con el Ministro de Dinamarca, General Raastoff, un tratado de compra de Santhomas y San Juan, el cual fue aceptado por el sufragio casi unánime de la población. E1 Gobierno danés relevó a sus súbditos de los deberes de lealtad y vasallaje. El Senado americano se negó a dar la aprobación. Es de recordar que años más tarde se opusieron los Estados Unidos a que las Antillas danesas fuesen vendidas a Francia.

E1 Gobierno americano celebró en $1 .^{\circ}$ de diciembre de 1884 , con el de Nicaragua, un tratado secreto, por el que se establecía el protectorado de la gran República sobre la pequeña. Según el artículo $10^{\circ}$ el canal había de ser 
construido por los Estados Unidos, y propiedad de ellos y de Nicaragua. El artículo $2 .^{\circ}$ decía:

Habrá una alianza perpetua entre los Estados Unidos de América y la República de Nicaragua, conviniendo la primera en proteger la integridad territorial de la segunda.

Se habían fijado dos años para que el Senado americano ratificara el tratado, que le fue prometido por el Presidente Arthur. El Senado no lo ratificó. Volvió éste a ocuparse en el asunto a principios de 1891, y tampoco le dio voto afirmativo.

E1 tratado secreto con el Ecuador, sobre las islas de Galápagos, de que hablé arriba, ni siquiera fue sometido al Senado con el tratado actual, referente a la isla Catham, del mismo grupo; a la hora en que escribo sólo sé que el Senado resolvió que no era asunto urgente, y lo aplazó para otra legislatura.

En marzo de 1885 dirigió el Senado una excitación enérgica al gobierno para que pusiera a raya al señor Barrios, Presidente de Guatemala, cuando éste decretó autoritariamente la Unión Centroamericana; la excitación no era de carácter obligatorio, y no fue atendida por el Presidente de los Estados Unidos en lo que tenía de violenta.

La guerra de Cuba, el atropello a ciudadanos americanos, ofrecieron a los Estados Unidos abundantes ocasiones para emprender algo contra la isla; cuando el apresamiento del Virginius, en 1873, se descompusieron de veras con España, y se aprestaron para la guerra, pero sin deseo vehemente, y nada hicieron por fin, sino cobrar dinero por sus ciudadanos muertos o saqueados.

En Colombia han tenido también varias oportunidades. E1 8 de marzo de 1880 presentó al Presidente Hayes el Secretario de Estado, Mr. William M. Evarts, una exposición en la que decía, y dejo la palabra al señor Céspedes (página 467):

Que en 1862 solicitó el Ministro granadino en Washington la intervención armada de los Estados Unidos contra el jefe revolucionario Mosquera, que había enviado tropas para ocupar el istmo de Panamá; que consultadas Inglaterra y Francia sobre ese punto, habían aconsejado la no intervención, por no haberse interrumpido el tráfico, sin que intervinieran, en consecuencia; que en 1864 hubieran intervenido si se hubiese presentado el caso de que las tropas españolas intentasen pasar el Istmo en las hostilidades contra el Perú; que en 1865 pretendió el Presidente de Colombia que los Estados Unidos protegiesen con la fuerza al Istmo contra la invasión de un cuerpo de insurrectos colombianos, y que se negaron a ello, fundados en que su compromiso se refería sólo a invasiones extranjeras y no a luchas interiores, en que no debían mezclarse.

En 1885 ordenó el Secretario de Marina, Mr. Whitney, al almirante Jóuetc que interviniera con su fuerza en otra guerra civil de Colombia, a solicitud de esta República.

Han podido, pues, varías veces los Estados Unidos ocupar provisionalmente el Istmo y quedarse en él, imitando ejemplos europeos, y recientemente las ocupaciones provisionales de Bosnia y Herzegovinia por Austria, y de Egipto por Inglaterra.

Del Canadá queda dicho ya que el Norte deseaba la anexión para sobreponerse a los Estados esclavistas: cuando la segunda guerra con la Gran Bretaña, allá por 1813, lo invadió con varias expediciones, y lo mismo durante la insurrección de 1837. Vencidos los confederados, esa razón dejó de subsistir, y antes bien 
se teme ahora que incorporada aquella región vigorice al Partido democrático, pues datan de muy atrás los vínculos transitorios y los permanentes que la ligan con el Sur, tales como la comunidad de agravios que a ambos irroga el proteccionismo imperante, y la del origen francés de gran parte de sus pobladores. Pero la opinión no es uniforme: otros ven en el Canadá un gran refuerzo para el sentimiento republicano, que no es el dominante en la inmigración europea, especialmente en la de irlandeses y alemanes meridionales, ni en la sociedad del Sur, donde aún subsiste el espíritu aristocrático que la esclavitud creó; mientras que los naturales del Dominio están acostumbrados al gobierno propio, y tienen sobre los pueblos de la América Latina la ventaja del idioma y la de la falta o escasez de negros. Blaine era de los que pensaban así. De los canadienses mismos es difícil saber cuál es la predominante entre las varias opiniones que sustentan; creo que el partido anexionista no es fuerte sino en las fronteras de los Estados Unidos; y lo seguro parece que la fidelidad a la Metrópoli se ha debilitado desde que ésta hizo saber a sus colonias que no pensaba gastar más dinero en ellas, $y$ que se arreglasen como pudiesen. Muchos están por constituirse en nación.

Por lo que hace a la República mejicana, recordaré algunos sucesos.

Mr. Mayes no jugó limpio con su vecina. El 4 de julio de 1877, en Wodstock (Conn.), denunció Mr. Blaine, en vigoroso discurso, la política, que llamó infame, de aquel magistrado y que consistía, según el orador, en promover dificultades a Méjico por asuntos de fronteras, para llegar a la guerra y despojarlo de más territorios. Ese discurso paralizó los planes de agresión, si en realidad existieron.

E1 viaje del General Grant en 1881 a esa República causó en ella mucha inquietud, porque se dijo que tenía por objeto promover la anexión. En un banquete con que los diputados de Oaxaca le obsequiaron, dijo el vencedor de Vicksburg que el pueblo americano de ninguna manera la aceptaría, ni aun cuando la pidieran las nueve décimas partes de la población mejicana, y agregó:

No tenemos necesidad de nuevas tierras; hay que mejorar las que poseemos, $\mathrm{y}$ queremos ver a nuestros vecinos prosperar y hacerse bastante fuertes para que los proyectos que respecto de ellos formen otros países no pongan en peligro su seguridad.

Las anexiones no constituyen, pues, aspiración de partido determinado, ni mucho menos nacional, como en Roma: son veleidades flotantes en el espacio y en el tiempo. Ni son cosa muy sencilla, porque en los Estados Unidos quien gobierna es la voluntad de la ley, no la de los hombres (¡dichosa República!). De sus hombres pudiéramos temerlo todo, ya que no se hallan exentos de las pasiones de nuestra especie; y esta distinción que el señor Céspedes omite, es principalmente lo que separa nuestros respectivos puntos de vista. Sí hay en la Unión gentes a quienes les toma gana de conquistar hasta los países imaginarios de Julio Verne; pero nuestro baluarte contra ellas son sus instituciones mismas, tales como las cimentó la última generación del siglo pasado.

Una anexión depende del movimiento acorde de un engranaje en que entran muchas ruedas. ¿La quiere el Presidente, como en el caso de Santo Domingo? Se opone el Senado. ¿Quiere el Senado alguna intervención que puede ir más allá, como cuando la dictadura de Barrios? Se opone el Presidente. ¿Están de acuerdo ambos, como a principios de este año, en los últimos días de la Administración Harrison respecto de las islas Hawai? Entonces se opone el pueblo mismo a quien se trata de absorber: Cleveland hizo respetar la voluntad del archipiélago. Caso ha habido, en fin, en que la ambición de un Presidente ha sido sofocada por un Secretario. Así sucedió cuando Pierce, a instigación 
de Soulé, se proponía arrebatar a España la isla de Cuba, piratería que no se consumó por la negativa resuelta de Secretario Marcy.

Sí hay, pues, lo repito, creyentes fervorosos del destino manifiesto; pero no predominan ni aun al disponer del Poder Ejecutivo, y eso se vio cuando $\mathrm{Mr}$. Blaine fue Secretario de Estado y casi dictador durante la enfermedad mortal de Garfield. ¿Qué ha quedado de todas sus combinaciones de expansión? Él mismo dijo en 1877 que las negociaciones de Santhomas y Santo Domingo fracasaron porque no se apetecen más territorios al Sur.

\section{III $^{3}$}

Nos parece que quedan establecidos los siguientes puntos esenciales:

1. Que la anexión es, por lo menos, muy improbable.

2. Que la intervención americana ha sido, en la mayor parte de los casos, antes favorable que no adversa a los pueblos de Hispanoamérica, 3. Que el poderío de los Estados Unidos es una salvaguardia para las Repúblicas americanas contra las absorbentes pretensiones de las Potencias europeas.

4. Que la anexión sería para los cubanos preferible a la continuación bajo el dominio español.

Situadas las cosas de esa manera, ¿qué republicano, qué americano puede desear el triunfo de España en la presente lid?

ElNacionalista, en un artículo escrito con ánimo sereno y elevado, lo reconocemos con gusto, plantea la cuestión así:

¿Qué es mejor para Cuba: una independencia absoluta, comienzo probable de una serie de guerras civiles, y ocasión tal vez de una anexión hace tiempo codiciada de parte del Leviatán vecino, o la autonomía ofrecida e implantada por el partido liberal de España, que parece reunir todas las ventajas de la independencia práctica y hallarse libre de todos sus inconvenientes?

Los cubanos contestan sin vacilar: la independencia absoluta, con todos sus peligros; otros querrán la sujeción parcial: cuestión de temperamentos. Pero hay una razón más poderosa todavía, y es ésta: entre la autonomía of recida por España en un momento de dificultades, y la autonomía efectiva y real, hay tanta diferencia como la que va de lo vivo a lo pintado, casi como lo que media entre las garantías eleccionarias, of recidas por los presidentes, y las que dan los alcaldes en nuestra patria.

Lo que pasó después del Zanjón, que no fue sino la repetición de lo que pasó con los Comuneros del Socorro, cerró para siempre el camino de las transacciones con España. Con Cartago no se puede pactar... Otra vez el señor Merchán:

${ }^{3}$ Publicado en La Opinión, 30 de abril de 1898. 
Si un día accediera España a implantar la administración autonómica, nada le costaría suprimirla al día siguiente.

Confesemos que tremendos y repetidos precedentes justifican la duda pavorosa que hace imposible ese camino.

\section{Dice El Nacionalista:}

Empeñada o inminente la lucha entre los Estados Unidos y España, hacemos votos por que la diplomacia europea encuentre todavía una solución que evite los desastres del conflicto y asegure el bienestar de Cuba.

Contestan los cubanos por centésima vez: la única solución que aceptamos es la absoluta independencia. ¿Acéptala España? Venga enhorabuena; evitáranse los terribles males de la guerra, y los dos pueblos hermanos se confundirían en ese abrazo de las naciones que cura todas las heridas y borra todos los odios.

Parece inútil repetir aquí que España no ha aceptado ni aceptará tal intervención. Cerrado este camino, toda intervención europea en el conflicto actual sería una odiosa repetición en América del drama de Creta. ¿Habrá republicano que pueda pensar en ello sin indignación?

Se levanta un pueblo cristiano y manifiesta con hechos heroicos su voluntad de sacudir el yugo de oprobio de Turquía y anexionarse al pueblo griego, a quien lo unen la naturaleza, la raza, la religión y la comunidad de gloriosas tradiciones. ¿Y qué hace Europa? Ayuda al turco, le da dinero y sacrifica al débil. Ni el océano del gran Neptuno podrá borrar esa mancha de la Historia, No, esto no pasará, porque el Derecho está por esta vez garantido por la firme voluntad de setenta y cinco millones de ciudadanos libres, ricos y fuertes. El absolutismo de las Potencias no prevalecerá por esta vez.

Eliminado el camino de la autonomía por la inquebrantable voluntad de los cubanos, ¿qué camino quedaba a la Unión Americana? ¿Podrá consentir en que la guerra dure indefinidamente? ¿Podrá mandar sus soldados a fusilar, en unión de los españoles, a los patriotas en la manigua?

Se arguye aún:

La guerra se prolonga indefinidamente en Cuba, gracias al apoyo de los Estados Unidos.

E1 Gobierno americano no apoyó nunca a los patriotas; apoyáronlos los ciudadanos, como lo hicimos, guardadas las proporciones, todos los americanos de Centro y Sur América. ¿Puede el Gobierno de Washington impedir que los particulares den su dinero para Cuba? No. ¿Puede impedir la compra de armas? No. Lo único que puede impedir es la salida de expediciones. Ante el Congreso demostró el Senador Morgan que se había gastado cerca de medio millón en 
la tarea verdaderamente enojosa de contener el entusiasmo de los americanos.

¿Puede un país aceptar, por modo indefinido, esta tarea? Debemos confesar que constituiría una verdadera servidumbre, a todas luces onerosa. Los Estados Unidos tenían perfecto derecho para hacer que cesase tal estado de cosas.

Concluyamos. En esta lucha entre la libertad moderna y el sistema colonial con que se busca el apoyo a la monarquía, debe triunfar y triunfará la libertad, porque es más fuerte, y en eso cabalmente ha consistido el progreso.

España misma encontrará su redención en esta derrota. Sus gobiernos tendrán que vivir en adelante del pueblo, y dejará de ser la piratería en el Exterior el medio de alimentar una realeza que el pueblo detesta porque lo explota, lo tiraniza, lo corrompe y lo degrada. Las colonias para España han sido lo que el huano para el Perú y el papel-moneda para las tiranías suramericanas.

En otra ocasión veremos la sustancial diferencia entre la colonización inglesa y la española. 